\title{
Play to learn: Self-directed home language literacy acquisition through online games
}

\author{
Susana A. Eisenchlas*a ${ }^{\mathrm{a}}$, Andrea C. Schalley ${ }^{\mathrm{a}}$ and Gordon Moyes ${ }^{\mathrm{b}}$ \\ ${ }^{a}$ School of Languages and Linguistics, Griffith University, Australia \\ ${ }^{\mathrm{b}}$ Griffith Film School, Griffith University, Australia \\ *Corresponding author’s email: s.eisenchlas@griffith.edu.au
}

\begin{abstract}
Home language literacy education in Australia has been pursued predominantly through Community Language Schools. At present, some 1,000 of these, attended by over 100,000 school-age children, cater for 69 of the over 300 languages spoken in Australia. Despite good intentions, these schools face a number of challenges. For instance, children may lack motivation and perceive after-hours schooling as an unnecessary burden. Trained teachers and suitable teaching materials are often not available. Moreover, not every language can be offered in each city or region. Hence, home language speakers' needs are often not met. This situation has detrimental effects for children, families and communities, and entails a loss of opportunities for the country. Reporting on an alternative approach, this paper presents a pilot study conducted in Australia with English-German bilinguals. We sought to investigate whether primary school-aged children can self-direct their home language literacy acquisition through playing online educational games, in the privacy of their homes and with little adult input. Results indicate that the games can be effective in promoting emergent literacy development. Thus, such a grassroots approach could become a viable option for multilingual societies, addressing some of the practical challenges faced by, for instance, Community Language Schools.
\end{abstract}

\section{Keywords}

multilingualism, literacy, self-directed acquisition, home language, educational games 


\section{Introduction}

Australia is one of the most multicultural and linguistically diverse nations in the world. As Welch put it, 'with the exception of Indigenous groups, Australians are all migrants' (2007, 155). ${ }^{1}$ According to the 2011 population census, almost 6 million migrants born in over 200 countries live now in Australia. The census further distinguishes between 'first generation Australians', i.e., overseas-born people living in Australia (27 percent of the population); 'second generation Australians', i.e., Australian-born people living in Australia with at least one parent born overseas (20 percent of the population); and 'third-plus generation Australians', Australianborn people whose parents were both born in Australia (53 percent of the population).

As to languages spoken, 19 percent of the Australian population aged over five years speak languages other than English at home. Moreover, almost half (49 percent) of longer-standing migrants and 67 percent of recent arrivals $^{2}$ speak a language other than English at home (Australian Bureau of Statistics 2012a; Eisenchlas, Schalley, and Guillemin 2013, 1). More than 300 migrant languages are spoken around the country.

Yet while Australia has made impressive advances since the days of the 'White Australia Policy', ${ }^{3}$ the status of languages other than English seems to be sliding backwards. ${ }^{4}$ As in many other countries of migration, the languages spoken by first generation Australians are not supported in the Australian education system (Eisenchlas, Schalley, and Guillemin 2013). As Piller (2013) argued, the few language-related policies in place take a deficit view of migrants and their languages and focus on improving English proficiency at the expense of proficiency and literacy in other languages. No attempts are made to invest in meaningful bilingual education that would enable bilingual children to achieve high levels of proficiency in their home language(s). ${ }^{5}$ Parents are often left to take on this task themselves, but they may lack the educational resources and/or the expertise to succeed. As a result, very few first and second generation Australian children can read or write in their home languages (Smolicz, 1999).

This impacts substantially on the maintenance of the home languages. In fact, Australia is known for producing high percentages of language attrition rates (Clyne 2001; Lo Bianco 2003), as also reported in the 2011 census. ${ }^{6}$ Writing is a highly fragile skill in linguistic minority situations, as it is not generally seen or needed in daily life and its maintenance requires constant use and practice (Clyne et al. 1997; Oriyama 2011). Over time, the lack of institutional support results in varieties of community languages that are limited to a narrow repertoire of styles and registers, and restricted to low-level functions and private sphere interactions (Valdés 2001; Gibbons and Lascar 1998). As Smolicz observed, when a language is reduced in its functions, the culture loses attraction for educated youth, as the language is 'unable to contribute actively to creative cultural interaction and development' (1999, 28). He further argued that loss of the native language heralds a cultural shift for communities, where ethnic groups may be maintained by appeal to their folklore and traditions, but where the intellectual aspects of culture evaporate and thus cultures become 'residualized'. Moreover, lack of support for home languages deprives children 
of the cognitive, academic and affective advantages associated with bilingualism (discussed in the next section), and can result in intergenerational conflict within families and communities.

From a utilitarian perspective, failure to support home languages in an institutionalized way, at the hand of national/subnational policy, is costly. It can cause loss of economic and other opportunities for a nation at large, as few of its people develop the advanced language proficiency needed to communicate successfully in the globalized world. This is true for Australia, which depends heavily on international trade (Australian Bureau of Statistics 2012b) ${ }^{7}$ and seeks to be included economically and geostrategically in the Asia-Pacific group of nations (Goldsmith and Dun 1997; Keating 2000; Smith 2009). Concerned parties make periodic calls to extend and improve language teaching, to strengthen the place of languages in the curriculum, and better position the nation with language capability. Yet recognition of the value of language education has not been firmly embedded in policy or politics. Without this, languages cannot gain the necessary foothold; Australia fails to uphold a clear, consistent national language policy.

In his oft-cited essay, Ruiz (1984) identified three perspectives that inform language policy orientation in the US and Canada: language as a right, as a problem, and as a resource. These perspectives also apply in Australia. A few 'modern' foreign languages, seen as resources on the basis of economic, geopolitical or cultural rationales, are distinguished clearly from indigenous, migrant and community languages that are seen as problems (Lo Bianco 2003). ${ }^{8}$ Furthermore, programs to develop the languages seen to be of economic significance target foreign language instruction at beginner levels; no special provisions are in place to develop the literacy skills of children who already speak these languages. Thus, valuable linguistic resources are lost.

In a thought-provoking article, Herscovitch (2012) discussed Australia's language needs for successful engagement with the Asian Pacific region. He argued that instead of attempting to attract $a b$ initio students into language programs, which seems increasingly like fighting an uphill and unnecessary battle, Australia should focus on its pool of migrant speakers of those languages. This argument can be extended beyond Asian languages and economic rationales. While we disagree that Australia should abandon foreign language programs, we do agree that increased support for maintaining and developing community languages will be highly beneficial for the country as a whole. This requires stronger commitment to fostering literacy in community languages. In light of the philosophy and content of Australia's current educational policies, however, it is unlikely that community languages will be made more prominent in the curriculum. Thus, migrant and refugee communities may need to develop initiatives themselves to cater for the linguistic needs of their children, and this is what we seek to support with our work.

This paper investigates to what extent primary school children can self-direct their literacy acquisition in the home language through playing online educational games in the privacy of 
their homes and with little adult input. The paper is organized as follows. After a brief review of the benefits of home-language literacy, we discuss the teaching of community languages in the Australian context and summarize the findings of previous studies on the effectiveness of online games on literacy acquisition, which guided our conceptualization of the current project. We then describe the pilot study conducted with German-English bilinguals, focusing on its implementation and preliminary findings, and suggest directions for further development.

\section{Some benefits of home language literacy: A very brief overview}

The literature presents broad and clear consensus that many cognitive, academic, social, and even financial (Agirdag 2013) advantages result from literacy in the home language, not only for the speaker but also for the community. Due to length considerations here, we restrict our discussion to advantages for the bilingual student. ${ }^{9}$

From a cognitive perspective, research has shown that acquiring literacy in the home language brings with it general cognitive and academic advantages for bilinguals that extend beyond the linguistic domain (Baker 2006). Areas 'in which this claim has been tested include metalinguistic awareness, phonological awareness, working memory, ability to decode and interpret text, in particular, when the writing systems differ across languages, and enhanced attention and concentration, among other skills' (Eisenchlas, Schalley and Guillemin 2013, 4; see Bialystok 2001 for a thorough review of the literature).

From an academic perspective, research shows that initial literacy in the home language facilitates rather than hinders the development of literacy in the majority language, as children are able to transfer the literacy skills acquired in the familiar home language into the majority language. ${ }^{10}$ For this to happen, though, children must achieve adequate proficiency levels in both languages (see Cummins' [1979] threshold hypothesis). Achieving adequate levels of proficiency in the home language is thus a specific and necessary criterion for attaining the cognitive and academic benefits that bilingualism offers. Conversely, denying children the benefits of literacy in their home language may result in a state that Hansegård (1975) has called 'semi-lingualism', the inability to express themselves in writing in any language. ${ }^{11}$

Furthermore, scholars also agree that children who are initially introduced to basic literacy in their home language learn a second language better than those who have no such solid foundation in the first language (Troike 1981; Hakuta and Gould 1987), and that first language literacy plays a crucial role in second language learning (Miller 2011). Moreover, in their study of third language acquisition, Swain et al. (1990) found statistically significant differences between children who were literate in their home language and those who were not. They found that home language literacy had a positive effect on third language learning overall, and not just on literacy in the third language. For these authors, the crucial element was the children's ability 
to read and write in the home language (whether they use this ability or not) rather than their oral proficiency. These authors argued 'there is an effect of first language literacy per se independent of first language oral/aural language skills, independent of general level of HL [Heritage language] proficiency, and independent of the linguistic/historical relationship between the two languages)' (Swain et al. 1990, 120). They concluded that 'when the second language is required for academic success and participation in the target language society, the provision of a sound first language basis which includes literate activities is a wise investment' (p. 120), particularly in light of current economic goals and priorities of Australian governments.

From an affective perspective, maintenance of the home language has been linked to speakers' higher personal and collective self-esteem, as it enables the home traditions and culture to be accessed, reproduced and transmitted (Clyne 1991; Fishman 1991; Oriyama 2011). High selfesteem may result in better academic performance in the long run, as studies have shown positive correlations between self-esteem and academic achievement (Makin, Campbell, and Jones Diaz 1995; Wright and Taylor 1995).

If the findings of these studies are accepted, it becomes clear that all languages are resources, not problems, even if the financial gain of some of these languages is not immediately evident. As many of the linguistic resources of Australia lie partly in the speakers of those languages, not supporting the development of literacy skills in home languages seems akin to 'throwing away the gift of the gods' (Smolicz 1999, 81). ${ }^{12}$

\section{Community languages education in Australia: Challenges}

We recognize that supporting home language literacy in most if not all of the languages spoken in Australia poses a significant challenge to the formal education system. Some home languages lack trained educators and teaching materials or they may be spoken only by small numbers of speakers. Furthermore, doubts have been cast on the ability of schools to cope with the complex Australian linguistic situation. Baldauf (1993), for instance, argued that the time on task required to attain even minimal vocational proficiency may be beyond what schools can provide. Similarly, Fishman (1991) recognized that schools alone cannot reverse language shift, and suggested steps for communities to create an environment in which home languages can thrive beyond the classroom.

Ethnic Schools, in operation since 1857, are a community response to these challenges. Also called 'ethnic', 'heritage', 'community run' or 'Saturday/Sunday' schools, their association's website describes them as 'after hours language schools that provide mother tongue language teaching and cultural maintenance programs' (Australian Federation of Ethnic Schools Associations, 2012). Australia now has about 1,000 community language schools, attended by more than 100,000 school age children. These schools provide lessons in 69 languages, just 
over one third of the languages spoken in Australia. The schools face many challenges. For instance, language tuition is usually conducted in addition to mainstream schooling, such as on Saturday or Sunday mornings, so many children perceive this as an unnecessary additional academic burden. Also, the diversity of proficiency levels of home language speakers across different ages poses logistical problems. Moreover, due to the linguistic diversity in Australia, most languages are offered only in some cities or regions, and hence Community Language Schools cannot meet the needs of speakers of every language spoken in Australia.

Against this background, Eisenchlas, Schalley, and Guillemin $(2013,7)$ suggest that any literacy support programs for home-language speaking children should follow a set of principles that cater to learners' needs (principles i-iii) and ensure effective design and implementation (principles iv-vii). The programs should be:

i. engaging and motivating, so children enjoy the experience and are intellectually stimulated; yet

ii. non-threatening, to avoid frustration;

iii. culturally relevant and appropriate, to draw on children's immediate experiences;

iv. easily adaptable, to cater for differences in levels of proficiency, languages and ages;

v. flexibly accessible at different times and locations of the children's choice;

vi. cost effective; and

vii. easy to maintain and expand.

Since trained teachers and/or language-relevant tuition are not available in some areas, these programs should also allow for autonomy and self-directed learning. Gaming environments fulfil all of these characteristics. The question is, then: are online games effective tools to develop home language literacy? This question is the focus of the present pilot study and is explored in the remainder of the paper. Before presenting the results of our pilot study, we provide a short overview of previous studies on the effectiveness of online games for literacy acquisition more generally.

\section{Effectiveness of online games for literacy acquisition: Previous studies}

Nowadays computers are ubiquitous in the school system. Computer literacy is increasingly recognized as one of the key skills students need to develop. As Miller (2011, 453) argued, 'the use of technology [is] one of the leading mandated innovations of the past decade in policy and curriculum and pedagogy'. In Australia computers are also easily available at public libraries, and some schools are providing children with tablets to use at home. Therefore, access to this technology is generally not restricted.

Furthermore, studies in marginalized Indian and African communities have shown that children can easily acquire computing skills without adult intervention (e.g., Gush, Cambridge, and Smith 2004; Mitra and Vivek 2001; Mitra et al. 2005). More important for our purposes, researchers 
have shown that playing computer games can facilitate literacy development. Van Daal and Reitsma (2000), for instance, investigated the use of computers to provide individualized instruction adapted to the needs of two different groups of students: precocious kindergarten readers (pilot study 1 ) and reading-disabled children who also had motivation problems (pilot study 2). The program used was Lesscircus ('circus of reading'), a multimedia program fully adaptive to boost independence in learning to read and spell. This goal was achieved by providing beginning readers and children who have reading problems with exercises designed to stimulate skills identified as important to successful reading acquisition. Participants in pilot study 1 learned in up to 16 hours of computer practice (in reality, however, only between 1.5 and 6 hours for most children) as much as is normally attained in the first three months of formal reading instruction in the classroom (around 30+ hours). The most important finding in pilot study 2 was that the amount of non task-directed behaviour of those who had practiced with the computer significantly decreased during both computer sessions and classroom sessions.

Similarly, Lyytinen et al. (2007) investigated if reading acquisition can be facilitated by using Literate, a computer game developed in Finland as preventive literacy training for children considered at risk, to be used independently of parent or teacher supervision. Two pilot studies were conducted with non-readers who started to play the game at the age when children in Finland enter school (six or seven years). The total playing time varied from one to four hours depending on the child's need and playing motivation. All the players were selected from children screened for the study, who did not read or whose reading ability was minimal. The children played 10-20 minute sessions at least a few times per week to ensure a total playing time of not less than 60 minutes. Children who played the Literate game were found to achieve statistically significant improvements when compared with the control group; non-reading children acquired basic reading skills after less than four hours of gaming.

While the studies described above focus on acquisition of literacy in the mainstream language, Kachenga (2008) reported on the use of the Zambian version of the Literate game to improve English reading ability in Zambian children. Sixty children from grades 3 and 4 with poor reading skills participated in this study. Thirty of them (intervention group) played the Literate game in English while the other 30 (control group) continued with normal school instruction (in each group, half of the participants were from grade 3, the other half from grade 4). The grade 3 students had a background of literacy skills learning in the local language (Cinyanja) whilst the grade 4 students had learned literacy skills straight in English (Kachenga 2008, 1). Kachenga found that using the game was effective for children in acquiring English literacy. Children 'seemed to benefit more from the short exposure [about three hours, the authors] to the Literate game in reading than they comparably learn during years at school' (Kachenga 2008, 20).

Finally, and significantly for our purposes, is evidence that young children (kindergarten through grade 3) can self-regulate their behaviour (e.g., planning, monitoring, problem solving and 
evaluating) when engaged in complex reading and writing tasks, in both the mainstream language (Perry, Nordby, and VandeKamp 2003) and foreign/second language acquisition (e.g., Mackey 1991).

While the studies summarized above seem promising, most studies have focused on mainstream literacy acquisition (e.g., van Daal and Reitsma 2000; Lyytinen et al. 2007) or foreign language acquisition (e.g., Kachenga 2008). Most of the previous studies were integrated into the school system, and they were used overwhelmingly to supplement classroom activities. To the best of our knowledge, no study so far has explored self-directed literacy development by young children in their home language. The aim of the present study is to address that gap.

\section{Our pilot study}

\section{Aim}

As we see from the brief overview of studies discussed above, ample evidence reveals that online games are effective in enhancing basic literacy skills. ${ }^{13}$ The studies mentioned, however, were conducted at school and integrated into the academic curriculum. This pilot project aimed to investigate whether children can self-direct their emergent literacy development in the home language through the use of online games in the early years of education, independently of the school environment and with minimal parental intervention. If feasible, this model could become a viable option for the Australian context, bypassing the need for both trained teachers and suitable materials in many of the community languages.

\section{Participants}

The participants in this study were nine middle-class, second generation German-English bilingual children (five boys and four girls) aged five to eight years. ${ }^{14}$ Five other children were tested in the control group, but did not play the online games. Participants were recruited through mailing lists of German-speaking play and parent groups in Brisbane, Australia. By the time the study was conducted, all children had already started schooling in Australia. The level of German oral proficiency, tested before the pilot started, varied, and for most children English was their dominant language. Children played independently at home at their own leisure during the time the pilot was conducted.

\section{Materials}

Three online games in German, titled Bubbles, Zoo, and Handball, were designed for this study.

\section{(a) Bubbles}


In this game, players read and listen to a question or description (presented in both audio and written format). They have to find the object or characteristic that matches the question/description. Examples include questions such as Wie heißt ein großes Auto, in dem ganz viele Leute sitzen können? 'What do you call a large vehicle in which many people can sit?' (expected answer: Bus 'bus'), and descriptions such as Nicht die Mutter, sondern der ----- 'Not mother, but ------' (expected answer: Vater 'father'). Culturally relevant descriptions are also included, such as Da kommen das Kasperle, der Räuber und der Polizist drin vor 'Kasperle, the thief and the policeman appear in this one' (expected answer: Kasperletheater 'Punch and Judy show'). From the beginning of each level, bubbles with letters on them appear on the screen. By clicking on the bubbles, players have to pop those bubbles that allow them to spell the word for the object/characteristic correctly. The faster the players pop the bubbles, the more points they earn. The scoring system ignores incorrectly popped bubbles, though players are indirectly penalized in that their popping takes time. Players play against two artificial intelligences that also try to pop the right bubbles. After players finish, the correct word appears in big letters on the middle of the screen, as feedback for the player.

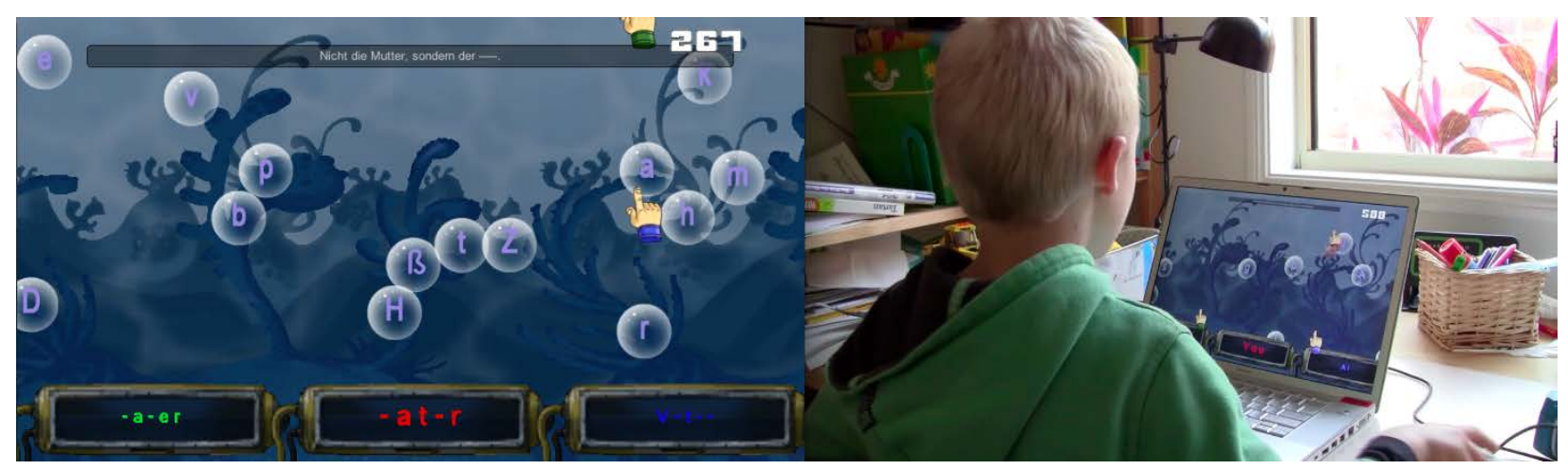

Figure 1. The Bubbles game (screen-shot and participant playing the game)

(b) Zoo

In the Zoo game, the task is to repair the signage of a zoo. Players see a direction sign inside the zoo with a picture of an animal (e.g., a kangaroo) and hear the name of this animal (audio format only). They have to correctly spell the name of the animal. A selection of letters falls down from the top of the screen, and players have to drag and drop the right letters into the appropriate positions to spell the word correctly. On some levels, they have to choose from a selection of letters of which only one is correct; on other levels only letters that are part of the word appear and the child has to sort these letters into the right order. Only correctly placed letters are accepted, otherwise letters do not stick to the sign and keep falling down until placed to spell the animal correctly. The faster the player works, the more points they achieve. Once completed, all letters are highlighted again, and the spoken word is repeated as feedback. 


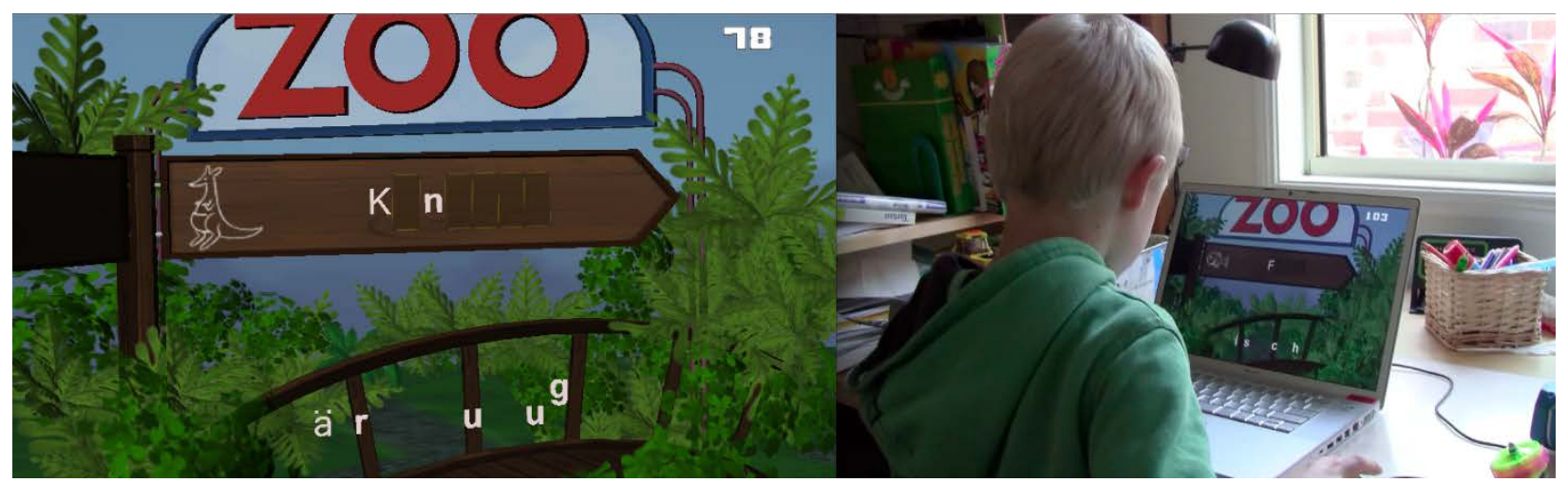

Figure 2. The Zoo game (screen-shot and participant playing the game)

\section{(c) Handball}

The third game was modelled on a sport that is quite popular in Germany - European Handball. Here a question (in audio and written format) is provided at the beginning. Handballs fall down into the visual field, each showing a letter combination. Players have to choose which of these letter combinations correctly answer the question and click on those balls to throw them into the goal. If they choose a wrong answer, the ball misses the goal. Questions include general ones such as Was findest Du alles auf der Baustelle? 'What is being used on a building site', as well as linguistic ones such as Bei welchem Wort hörst Du ein 'sch' am Anfang? 'Which word starts with the sound 'sh'?', Was ist richtig geschrieben? 'What is spelled correctly?', or Was reimt sich auf 'Haus'? 'What rhymes with "house”?'. Players win 10 points for each correct ball, but lose 20 points for selecting a wrong answer. They play against one artificial intelligence. At each level's end, a feedback screen shows the player's correct and incorrect answers.

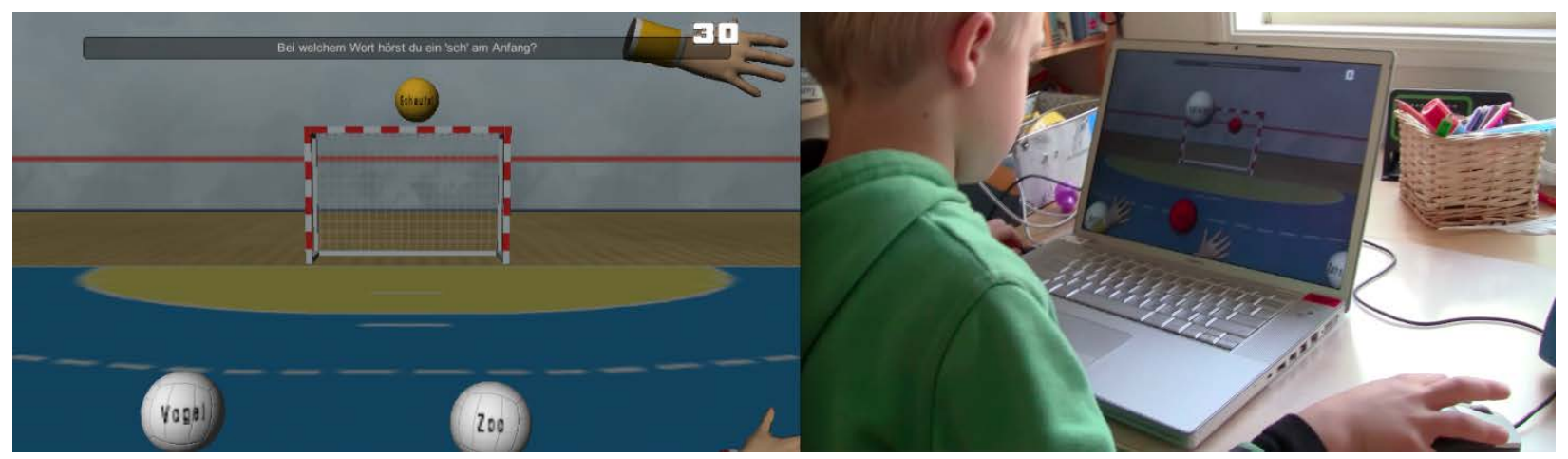

Figure 3. The Handball game (screen-shot and participant playing the game)

The games are aimed to develop basic literacy skills rather than other areas of language development, and they assume the player has some knowledge of the language. Their development was based on well-respected models of German literacy acquisition (Brügelmann and Brinkmann 1994; Spitta 1998). Targeted skills comprise letter recognition, spelling and reading words, recognition of rhymes and constituent sounds, and so on. They include tasks practicing German phonics awareness in general and specific German orthographic rules around 
multigraphs, capitalization, German-specific letters ( $\ddot{a}, \ddot{o}, \ddot{u}, ß)$, terminal devoicing, double consonants for sharpening (e.g., $p p$ or $f f$ ) and lengthening (e.g., ee), length markers (e.g., $h$ ), and $s t$ and $s p$ for representing $/ \mathrm{ft} /$ and $/ \mathrm{s} \mathrm{p} /$, respectively.

All three games entailed an element of competition: a clock keeping time in Bubbles and Zoo, and artificial intelligences playing against the children in Bubbles and Handball. Players' scores for each level were recorded and accessible on the level selection screen of each game, so players could intentionally go back to those levels where they wanted to improve their scores.

\section{Procedure}

The study involved a number of steps:

After identifying the potential participants through social networks such as German playgroups and parent groups, a face-to-face demographic interview was conducted with parents to obtain information on the families' patterns of language use and the parents' linguistic goals and expectations, which presumably would inform their family language policy and practices. A folder containing the consent form, account information, and login details to access the games, and an observation protocol for parents to complete while children were playing the games were provided to parents following the interview.

A German trained primary school teacher conducted in German an initial assessment of the children's German with all children in the participant and control groups. The assessment consisted of two main sections: 1) an investigation of the child's German proficiency levels in both comprehension and production, based on the Berliner Sprachstandserhebung 'Bärenstark' [Berlin Language Development Survey] (Senatsverwaltung für Bildung, Jugend und Sport 2002); and 2) a literacy test, which included a free writing task, a picture dictation task and a rhyming activity. Children who showed they had some reading ability also completed a reading comprehension test of both words and sentences. This provided us with insights into both their language development and their literacy skills in German. Following the test, the children in the participant group were introduced to the games and given an evaluation sheet where they recorded their feelings about the games they played by selecting a face showing one of a range of emotions (from bored to happy).

Children played the games during a two to three week period (depending on participants' availability), at home, with or without parents present. Data was collected during that period from three different sources: 1) parents' observations and notes taken on their children's reactions to the games; 2) children's own evaluation of the games every time they played; and 3) automatic tracking of game events each time children played. Information recorded by the tracking system included frequency and length of play, which games children played, and how 
they performed in terms of success on task and speed. Game snapshots taken at one second intervals allowed us to recreate how children played each game and were thus instrumental in documenting how the children's learning occurred. ${ }^{15}$

The data collection period was followed by a post-test evaluation of German literacy, which included the same types of tasks as the pre-test (i.e., dictation, free writing and rhymes) plus a syllable ordering task. Both pre- and post-tests were audio recorded. Parents were also interviewed about the games and their suitability, as well as about their observations on the strategies children used while playing.

\section{Results}

Both the parents' observations and notes and the children's feedback revealed satisfaction and positive evaluation of the games. Children particularly liked the immediate feedback provided during play. An unexpected lesson for us was how much children enjoyed the competitiveness of the games, provided, as mentioned above, by the artificial intelligences (that gave some children the idea they were competing against other children) and the on-screen clock keeping time (that motivated children to 'beat it' and improve their times, thus competing against themselves). Competitiveness is a feature usually missing from educational online games or other interactive programs designed for young children.

More importantly, the data provided evidence of German literacy development as a result of playing the games. It could be argued that gains through English literacy instruction explain the changes in German literacy that the data revealed. Granted, all of the participant children had already started schooling at the beginning of the school year during which testing was conducted or even in the previous year or two. However, the data include examples of learning that are not explained as simply a transfer from English literacy instruction into German. We discuss one of these examples below.

For the purposes of this paper, we focus on data obtained from two boys, A and B, who were the youngest (five years) and oldest (eight years) in the participant group. These boys were also the most frequent players and played the games at all levels. Both had a high level of German language proficiency. For comparative purposes, we also present results from one girl, C, aged 5, whose level of German language proficiency was comparable with that of the two boys, but who as part of the control group did not play the games.

Table 1 summarizes the overall gaming of the two players A and $B$ ( $C$ did not play). As the percentages show in the table, both A and B spent most of their time playing Zoo, which had the largest number of game levels at 71 . Yet both boys were also drawn strongly to Bubbles and 
Handball, which they played at least twice (in some cases three times) at as many levels as the games offered.

Table 1. Time spent playing the games ${ }^{16}$

\begin{tabular}{lccccc}
\hline Player & Time played & Total records & Bubbles & \multicolumn{1}{c}{ Zoo } & Handball \\
\hline A & 4 h $40 \mathrm{~m}$ & 71,471 & $104(35.25 \%)$ & $118(40 \%)$ & $73(24.75 \%)$ \\
B & 2 h $25 \mathrm{~m}$ & 55,364 & $73(27.65 \%)$ & $128(48.49 \%)$ & $63(23.86 \%)$ \\
\hline
\end{tabular}

Note: 'Time played': each participant's accumulated actual playing time; 'Total records': number of game events the tracking system recorded; 'Bubbles/Zoo/Handhall: for each game, the number of levels the child played (out of $35 / 71 / 22$ levels, respectively) and, in brackets, the overall share of participant's playing for which this accounts.

Figures 4, 5, and 7 compare the pre- and post-test results of the dictation task of the three children A, B and C, respectively. ${ }^{17}$ Results for children A and B show evidence of consistent patterns of change, while child $\mathrm{C}$ showed no such pattern between the pre- and post-tests. For the youngest child A (Figure 4), we can find evidence of restructuring; the child consistently represented sounds that he perceived as longest or most prominent in a word through double or even triple letters in the post-test response (cf. Lllaaa for Leiter /laite/ or Bess. for Besen /be:zən/). He implemented capitalization of words more consistently with the target orthography: in the post-test he used upper case only on first letters of words (in this case, all nouns) and on none of the following letters as he had in the pre-test. Yet, interference effects from English to German can also be identified, such as the representation A of /ai/ in Eimer /aime/.

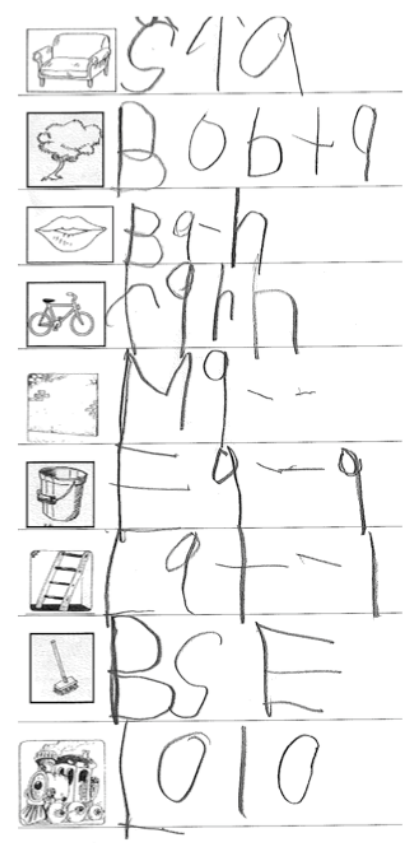

\begin{tabular}{|l|l|l|}
\hline Stimulus & Pre-test & Post-test \\
\hline Sofa & STa & Saa. \\
\hline Baum & Bobta & Baard. \\
\hline Mund & Ba-h & Nrra. \\
\hline Fahrrad & Farh & Frrar. \\
\hline Mauer & Ma-- & Maa. \\
\hline Eimer & Ea-a & Ama. \\
\hline Leiter & Lat-l & Lllaaa \\
\hline Besen & BSE & Bess. \\
\hline Lokomotive & Lolo & Lllakn \\
\hline
\end{tabular}

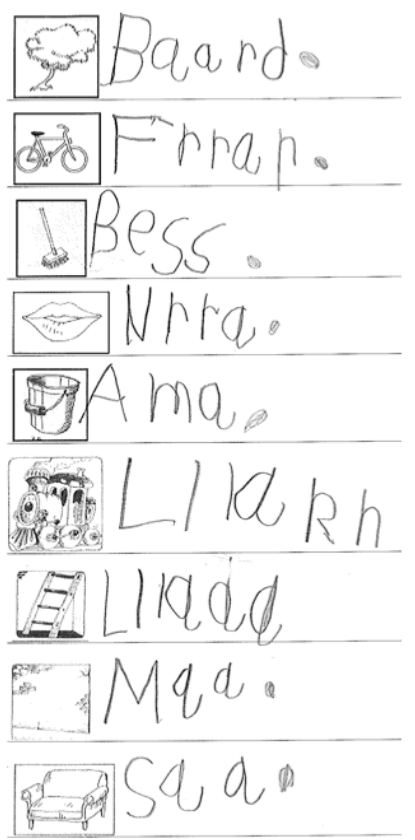

Figure 4. Pre- and post-test dictation results, child A (youngest player) 
The oldest child, B, (Figure 5) shows remarkable consistency in his general spelling of the words within and between pre- and post-tests. This in particular applies to the representation of $/ \mathfrak{e} /$ as $a$ at the end of words (such as in Eimer/aime/, Leiter/laite/, Mauer /mauv/), which shows that this child did not acquire all orthographic regularities in the short period of playing. Overall, soundletter correspondences are much more advanced than for child A, as would be expected given the age difference and the difference in the amount of formal literacy education these boys had received. For child B, we can also identify interference effects, such as the representation of $i$ for /ai/, e.g., in Lita for Leiter /laitp/. However, note the target form Ei for /ai/ in Eima, representing /aime/ in the post-test.

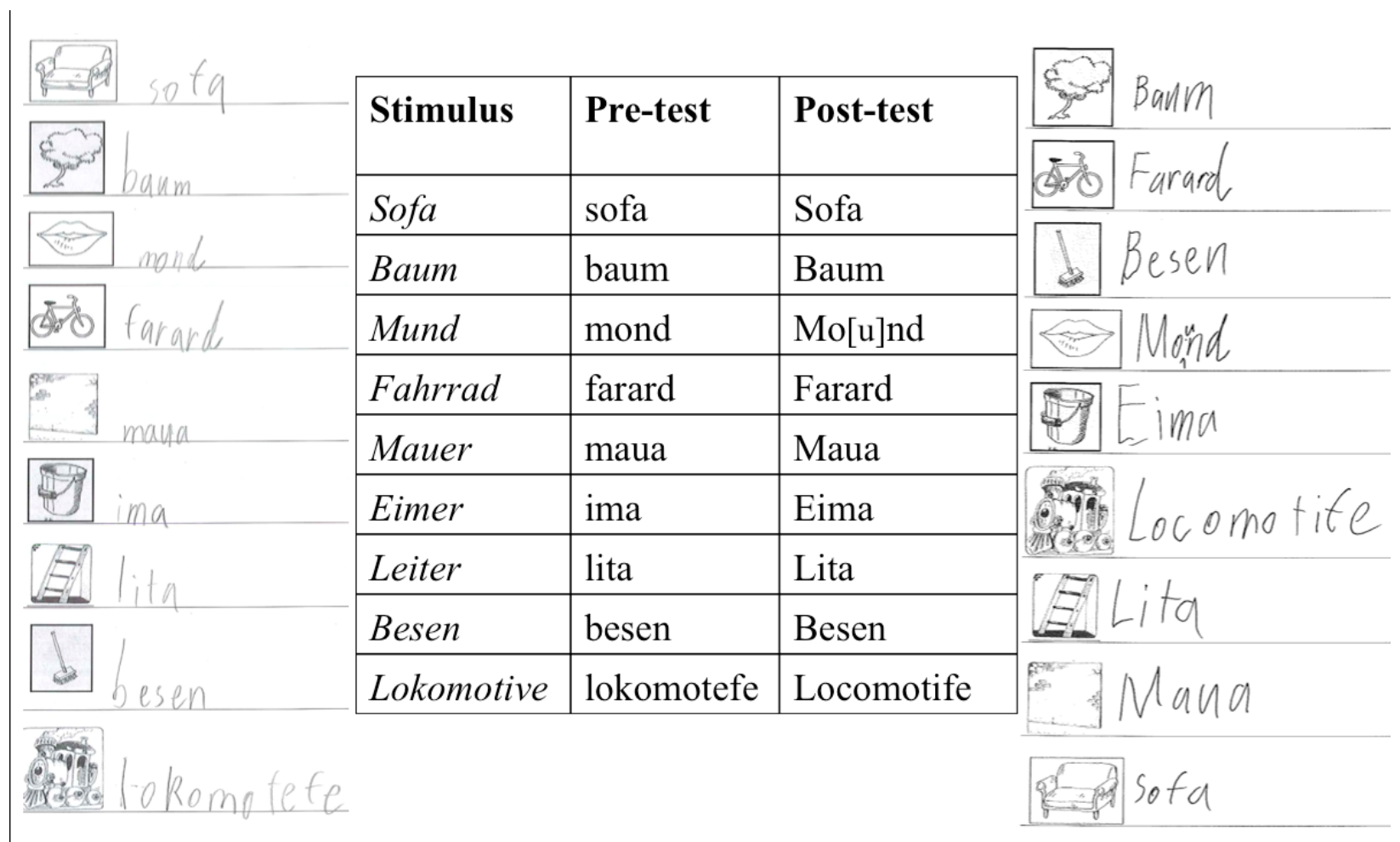

Figure 5. Pre- and post-test dictation results, child B (oldest player)

There is one clear example of learning that cannot be attributed to a transfer from English literacy instruction into German: the capitalization of German words for things. This is consistent with the target rule that nouns in German are capitalized (including nouns denoting things). Figure 5 shows that child B spelled all nouns with a lower case initial letter in the pre-test, but used upper case on the initial letter in the post-test (as per target forms). Further pre- and posttest data from child B (Figure 6) also provides evidence of this child acquiring ability to capitalize nouns. In the syllable ordering task (part of the post-test only), he has correctly positioned capitalized syllables as word beginnings. More impressive, though, are results of the free writing task. ${ }^{18}$ In the pre-test, child B lists three words, with no capitalization. In the post- 
test, he freely provides ten different words (note the substantial increase in number), capitalizing the first initial of all nouns, ${ }^{19}$ while the only non-noun, the adjective groß 'big, tall', he has spelled with a lower case initial letter. We also see in Figure 6 that child B first started writing some of the German nouns in the free writing post-test task with lower case on the initial letter, but then corrected himself to upper case initial letters (e.g., Sofa, Tea, Café, Wasser). ${ }^{20}$

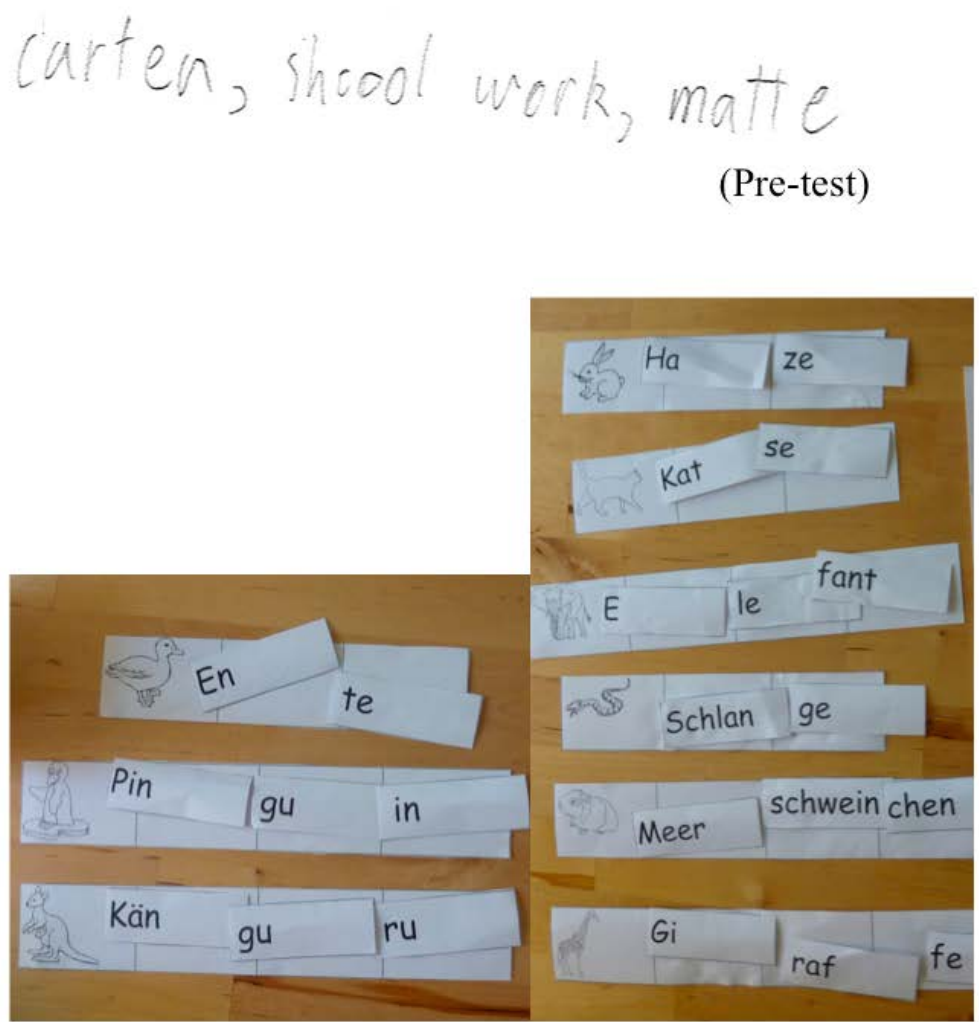

(Post-test)
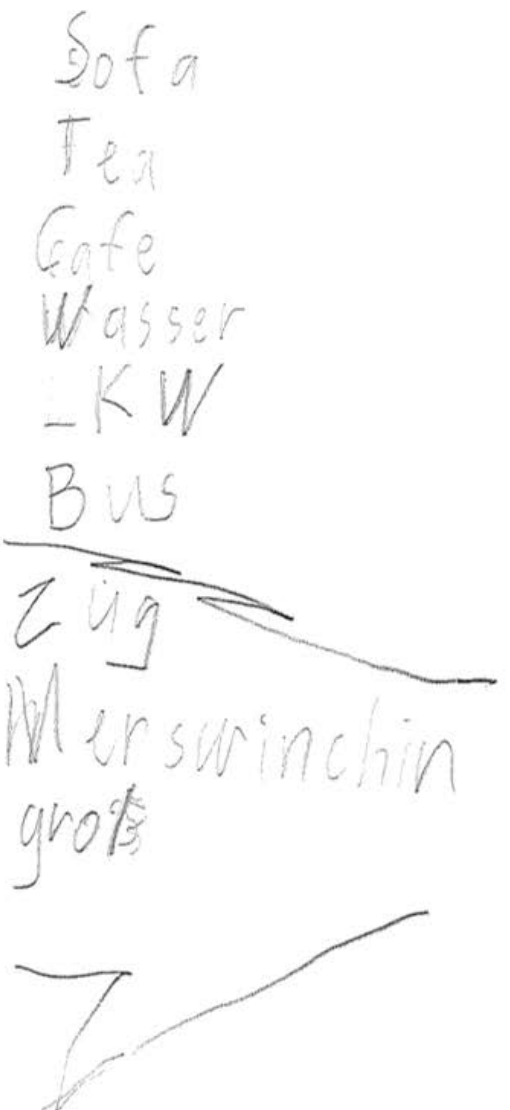

(Post-test)

Figure 6. Results of the pre-and post- test free writing task and post-test syllable ordering task of child B (oldest player)

Finally, data from the control group girl, child C, showed no consistent pattern of change between the pre- and post-test results (Figure 7). Moreover, data from free writing shows that from pre-test to post-test, child A and child B in the group that played the games increased the number of words they wrote spontaneously, but this was not the case for child C who did not play the games (who in both pre-and post-tests focused on producing her and her sister's names). 


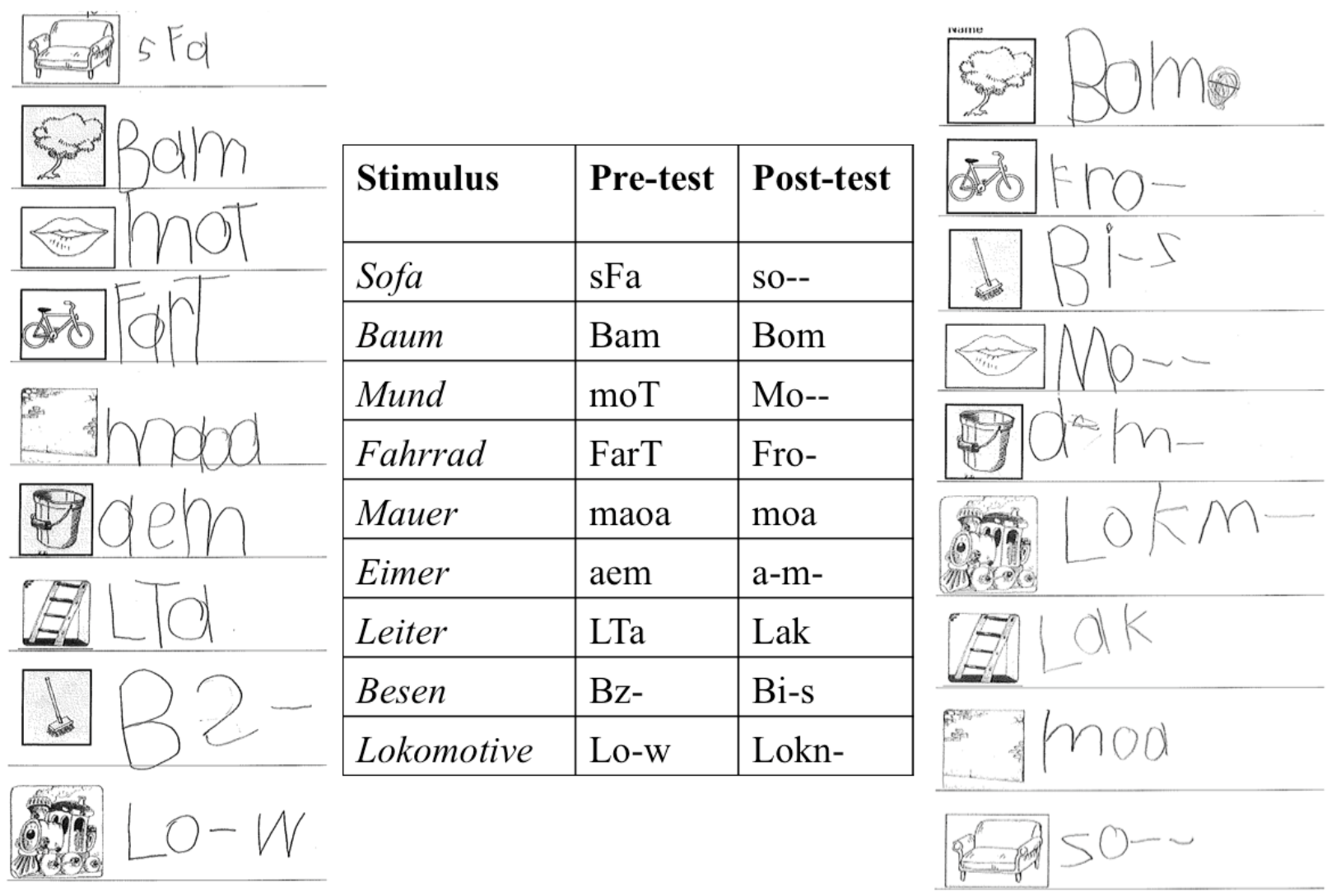

Figure 7. Pre- and post-test dictation results for child C (control group)

\section{Conclusion}

The results of this pilot study suggest that literacy skills in the home language of bilingual children can be developed in the early years of education through the use of online games, with children playing independently, in their own time and at a place of their choice. While this is a very promising outcome, the study itself was small-scale and hence more elaborate iterations will be required to investigate the effectiveness of the gaming approach. There are also two further caveats: all participants were middle-class children, and the games targeted only emergent literacy; results may differ across different demographics and literacy-related skills. We are currently working on moving both the pre- and the post-test into an online format, to be able to access a larger cohort of participants and to see whether this approach will be successful in the longer term. A larger cohort of participants will enable us to gather more sustained evidence. A longer playing period as well as continuous post-testing will enable us to more closely follow the learning trajectory of the children, and we can expect that it will also shed light on factors influencing children to take up the games and play.

Our hope is that the approach reported here may be able to cater for diverse languages in multilingual societies such as Australia. We are aware that the conclusions we draw from this study cannot simply be extended to other communities whose cultural interpretations and 
practices of literacy may differ from those of our study's participants (Richardson 1998). Further studies with other communities are therefore essential. Other factors that might impact on study results and thus deserve further investigation are the similarities/differences among writing systems to which children are exposed, as well as differing degrees of phonological transparency of the languages involved. Furthermore, children who participated in our study were not refugees, they had not suffered trauma in coming to their new country of residence, and they had not experienced severely interrupted schooling due to migration, all situations that may give rise to a different set of learning challenges for the children. Nonetheless, we remain optimistic that our approach complements existing efforts towards home language literacy development and provides families and children with an effective and supportive tool.

\section{Acknowledgements}

We gratefully acknowledge the support of Griffith University's Arts, Education and Law Collaborative Research Project Grant Scheme. We sincerely thank the reviewers of this paper for their helpful and detailed comments, which have helped to improve this paper considerably. Last but not least, we are indebted to Kirsten Hartel and Alexander Borkowski for their exceptional research assistance.

\section{References}

Agirdag, O. 2014. "The Long-term Effects of Bilingualism on Children of Immigration: Student Bilingualism and Future Earnings." International Journal of Bilingual Education and Bilingualism 17 (4): 449-464.

Australian Government Department of Foreign Affairs and Trade. 2011. Trade at a Glance 2011. Canberra: DFAT.

Australian Bureau of Statistics. 2012a. Reflecting a Nation: Stories from the 2011 Census, 20122013. [Accessed 4 December 2013]

http://www.abs.gov.au/ausstats/abs@.nsf/Lookup/2071.0main+features902012-2013

Australian Bureau of Statistics. 2012b. Australia in an International Context. [Accessed 4 December 2013] http://www.abs.gov.au/ausstats/abs@.nsf/Lookup/by\%20Subject/1301.0 2012 Main\%20Featur es Australia\%20in\%20an\%20international\%20context 209

Australian Federation of Ethnic Schools Associations. 2012. Community Languages Australia. [Accessed 18 September 2014] http://www.communitylanguagesaustralia.org.au/aboutus/ 
Baker, C. 2006. Foundations of Bilingual Education and Bilingualism. Clevedon: Multilingual Matters.

Baldauf Jr, R. B. 1993. "Fostering Bilingualism and National Development through School Second Language Study.” Journal of Multilingual and Multicultural Development 14 (1-2): 121-134.

Bialystok, E. 2001. Bilingualism in Development: Language, Literacy, and Cognition. Cambridge: Cambridge University Press.

Brügelmann, H., and E. Brinkmann. 1994. "Stufen des Schriftspracherwerbs und Ansätze zu seiner Förderung.” ["Stages of literacy acquisition and approaches towards supporting it.”] In Wie wir recht schreiben lernen [How we learn to write correctly], edited by H. Brügelmann and S. Richter, 44-52. Lengwil: Libelle.

Clark, M. 1987. A Short History of Australia. Ringwood: Penguin.

Clyne, M. 1991. Community Languages: The Australian Experience. Cambridge: Cambridge University Press.

Clyne, M., S. Fernandez, I. M. Chen, and R. Summo-O’Connell. 1997. Background Speakers: Diversity and its Management in LOTE Programs. Belconnen: Language Australia.

Clyne, M. 2001. “Can the Shift from Immigrant Languages be Reversed in Australia?” In Can Threatened Languages be Saved? Reversing Language Shift Revisited: A 21st Century Perspective, edited by J. A. Fishman, 364-391. Clevedon: Multilingual Matters.

Cummins, J. 1979. "Linguistic Interdependence and the Educational Development of Bilingual Children.” Review of Educational Research 49: 222-251.

Eisenchlas, S. A., A. C. Schalley, and D. Guillemin, 2013. "The Importance of Literacy in the Home Language: The View from Australia.” SAGE Open 3 (4). doi: 2158244013507270.

Fishman, J. A. 1991. Reversing Language Shift: Theoretical and Empirical Foundations of Assistance to Threatened Languages. Clevedon: Multilingual Matters.

Gibbons, J., and E. Lascar. 1998. "Operationalising Academic Language Proficiency in Bilingualism Research.” Journal of Multilingual and Multicultural Development 19 (1): 40-50. 
Goldsmith, D. J., and S. A. Dun. 1997. "Sex Differences and Similarities in the Communication of Social Support.” Journal of Social and Personal Relationships 14: 317-337.

Grosjean, F. 1985. “The Bilingual as a Competent but Specific Speaker-Hearer.” Journal of Multilingual and Multicultural Development 6: 467-477.

Gush, K., G. Cambridge, and R. Smith. 2004. “The Digital Doorway - Minimally Invasive Education in Africa.” [Accessed 18 September 2014]

http://www.digitaldoorway.org.za/publications/ICT\%20in\%20Education\%20conference\%20pap er-\%20The\%20Digital\%20Doorway_March_2004.pdf

Hakuta, K., and L. J. Gould. 1987. "Synthesis of Research on Bilingual Education.” Educational Leadership 44 (6): 38-45.

Hansegård, N. E. 1975. “Tvåspråkighet eller halvspråkighet?” [Bilingualism or Semilingualism?] Invandrare och Minoriteler [Immigrants and Minorities] 3: 7-13.

Hecht, S. A., and L. Close. 2002. "Emergent Literacy Skills and Training Time Uniquely Predict Variability in Responses to Phonemic Awareness Training in Disadvantaged Kindergartners.” Journal of Experimental Child Psychology 82 (2): 93-115.

Herscovitch, B. 2012. “Australia's Asia Literacy Non-Problem.” Issue Analysis 133 (5 September). Sydney: Centre for Independent Studies.

Hirst, K., P. Hannon, and C. Nutbrown. 2010. "Effects of a Preschool Bilingual Family Literacy Programme.” Journal of Early Childhood Literacy 10 (2): 183-208.

Judge, S. 2005. “The Impact of Computer Technology on Academic Achievement of Young African American Children.” Journal of Research in Childhood Education 20 (2): 91-101.

Kachenga, G. M. 2008. "The Effect of Using Computer Literate Game in the Teaching of Reading Literacy Skills in Zambia.” MA Thesis, University of Jyväskylä.

Keating, P. J. 2000. Engagement: Australia Faces the Asia-Pacific. Sydney: Macmillan.

Lo Bianco, J. 2003. “A Site for Debate, Negotiation and Contest of National Identity: Language Policy in Australia.” In Guide for the Development of Language Education Policies in Europe: From Linguistic Diversity to Plurilingual Education. Strasbourg: Language Policy Division DG IV - Directorate of School, Out-of-School and Higher Education Council of Europe. 
Lyytinen, H., M. Ronimus, A. Alanko, A. M. Poikkeus, and M. Taanila. 2007. "Early Identification of Dyslexia and the Use of Computer Game-based Practice to Support Reading Acquisition.” Nordic Psychology 59 (2): 109-126.

Macaruso, P., and A. Walker. 2008. “The Efficacy of Computer-Assisted Instruction for Advancing Literacy Skills in Kindergarten Children.” Reading Psychology 29: 266-287.

Mackey, W. F. 1991. "Language Education in Bilingual Acadia: An Experiment in Redressing the Balance.” In Bilingual Education: Focusschrift in Honour of Joshua A. Fishman, edited by Ofelia Garcia, 239-252. Amsterdam: John Benjamins.

Makin, L., J. Campbell, and C. Jones Diaz. 1995. One Childhood, Many Languages: Guidelines for Early Childhood Education in Australia. Pymble, NSW: Harper Educational.

Miller, J. 2011. “Teachers’ Work in Culturally and Linguistically Diverse Schools.” Teachers and Teaching 17 (4): 451-466.

Mitra, S., and V. Rana. 2001. "Children and the Internet: Experiments with Minimally Invasive Education in India.” British Journal of Educational Technology 32 (2): 221-232.

Mitra, S., R. Dangwal, S. Chatterjee, S. Jha, R. S. Bisht, and P. Kapur. 2005. “Acquisition of Computing Literacy on Shared Public Computers: Children and the 'Hole in the Wall'.” Australasian Journal of Educational Technology 21 (3): 407-426.

Oriyama, K. 2011. "The Effects of the Sociocultural Context on Heritage Language Literacy: Japanese-English Bilingual Children in Sydney.” International Journal of Bilingual Education and Bilingualism 14: 653-681.

Perry, N. E., C. J. Nordby, and K. O. VandeKamp. 2003. "Promoting Self-Regulated Reading and Writing at Home and School.” The Elementary School Journal 103 (4): 317-338.

Piller, I. 2012. “Comment on Schools Transforming Multilinguals into Illiterates?” (blog entry on Language on the Move) July. [Accessed 18 September 2014.] http://www.languageonthemove.com/language-learning-gender-identity/schools-transformingmultilinguals-into-illiterates/comment-page-1

Piller, I. 2013. “Monolingualism is Bad for the Economy.” Language on the Move. 4 December. [Accessed 18 September 2014.] http://www.languageonthemove.com/language-migration-socialjustice/monolingualism-is-bad-for-the-economy 
Richardson, P. 1998. “Literacy, Learning and Teaching.” Educational Review 50 (2): 115-134.

Ruiz, R. 1984. “Orientations in Language Planning.” NABE Journal 8: 15-34.

Schalley, A. C., S. A. Eisenchlas, and G. Moyes. (in preparation) "Games for Boosting Literacy in the Home Language: The How and Why".

Senatsverwaltung für Bildung, Jugend und Sport, ed. 2002. Berliner Sprachstandserhebung und Materialien zur Sprachförderung für Kinder - underckahsictyahngsphase [Berlin Language Development Survey and Language Support Materials for Children in Preschool and Reception Class]. Report, Berlin.

Skutnabb-Kangas, T. 2000. Linguistic Genocide in Education - Or Worldwide Diversity and Human Rights? Mahwah, NJ and London: Lawrence Erlbaum Associates.

Smith, S. 2009. "Australia and the Asia-Pacific Century.” Speech delivered on 14 August 2009 for the Griffith Asia Institute at the Gallery of Modern Art, Brisbane.

Smolicz, J. J. 1999. JJ Smolicz on Education and Culture. Edited by M. Secombe, and J. Zajda. Albert Park, Vic.: James Nicholas Publishers.

Spitta, G. 1988. Kinder schreiben eigene Texte. [Children write their own texts.] Frankfurt a. M.: Scriptor.

Swain, M., S. Lapkin, N. Rowen, and D. Hart. 1990. "The Role of Mother Tongue Literacy in Third Language Learning.” Vox 4: 111-121.

Troike, R. C. 1981. "Synthesis of Research on Bilingual Education.” Educational Leadership 38 (6): 498-504.

Valdés, G. 2001. "Heritage Language Students: Profiles and Possibilities." In Heritage Languages in America: Preserving a National Resource. Language in Education: Theory and Practice, edited by J. K. Peyton, D. A. Ranard, and S. McGinnis, 37-77. McHenry, IL: Delta Systems.

van Daal, V. H. P., and P. Reitsma. 2000. "Computer-assisted Learning to Read and Spell: Results from Two Pilot Studies.” Journal of Research in Reading 23 (2): 181-193.

Welch, A. 2007. “Cultural Difference and Identity.” In Education, Change and Society, edited by R. Connell, C. Campbell, M. Vickers, A. Welch, D. Foley, and N. Bagnall, 155-187. South Melbourne, VIC: Oxford University Press. 
Wright, S. C., and D. M. Taylor. 1995. "Identity and the Language of the Classroom: Investigating the Impact of Heritage Versus Second Language Instruction on Personal and Collective Self-Esteem.” Journal of Educational Psychology 87: 241-252. 


\section{$\underline{\text { TABLE }}$}

Table 1. [NOTE: CAPTION SEE IN TEXT, NOT REPEATED HERE DUE TO ENDNOTE]

\begin{tabular}{|l|l|l|l|l|l|}
\hline Player & Time played & Total records & Bubbles & Zoo & Handball \\
\hline A & $4 \mathrm{~h} 40 \mathrm{~m}$ & 71,471 & 104 & 118 & 73 \\
& & & $(35.25 \%)$ & $(40 \%)$ & $(24.75 \%)$ \\
\hline B & $2 \mathrm{~h} 25 \mathrm{~m}$ & 55,364 & 73 & 128 & 63 \\
& & & $(27.65 \%)$ & $(48.49 \%)$ & $(23.86 \%)$ \\
\hline
\end{tabular}


${ }^{1}$ Whether Anglo-Australians can be considered migrants is a matter of debate. In an interesting discussion, Smolicz $(1999,12)$ asked, "Could Captain Phillip [first Governor of the British penal colony of New South Wales and founder of the settlement that became Sydney in 1788] be viewed as a migrant?" His answer was "It would seem not, since migration generally implies prior permission to land, and none was asked at the time."

2 'Longer-standing' arrivals are those who arrived before 2007, and 'recent' arrivals those who arrived in the period from 2007 to the Census Night in 2011 (9 August 2011; Australian Bureau of Statistics 2012a, section on 'Cultural Diversity in Australia').

${ }^{3}$ The 'White Australia Policy' or 'Immigration Restriction Act' was the first Act of Parliament passed after Federation (1901). Its aim was to promote a homogenous population by restricting immigration to mainly northern Europeans (Clark 1987).

${ }^{4}$ In fact, according to Clyne (1991), bilingual education in Australia was better accepted in the nineteenth century than it is today.

${ }^{5}$ A number of alternative terms have been used in the literature (including 'mother tongue', 'first language', 'home language', 'native language', 'heritage language'). None of these is unproblematic. For lack of a better term, we adopt 'home language', the language acquired by the child through immersion at home.

${ }^{6}$ The census documents this process of home language attrition: while 53 percent of first generation Australians speak a language other than English at home, the proportion of second generation speakers is much lower at 20 percent, and lower still for the third-plus generation (1.6 percent). These figures indicate clearly that despite what some opponents may claim, the home language is not a threat to English.

${ }^{7}$ As Minister for Trade in 2010, Dr Craig Emerson claimed, “Australian exports generated more than 20 per cent of Australia's gross domestic product. Both exports and imports create employment: one in five Australian jobs is related to trade and expanding our international trade will help secure a high-skill, high-wage future” (Australian Government Department of Foreign Affairs and Trade, 2011).

${ }^{8}$ As Piller noted in a response to a blog (2012), there is a significant overlap between "foreign language" and "community language", as some of the most frequently taught "foreign languages" (Chinese, German, Italian, Japanese, Korean) are also major "community languages".

${ }^{9}$ Despite parents' and teachers' concerns that literacy in the home language may impact negatively on literacy in the mainstream language (e.g., through a possible confusion between writing systems), most researchers strongly emphasize the benefits of home language literacy (see Bialystok 2001 for a thorough review of the literature). ${ }^{10}$ It should be noted that transfer from the home to the mainstream language could be facilitated or hindered by the literacy practices the child experiences, e.g., at home and/or in a formal environment such as Sunday schools.

${ }^{11}$ The concept of 'semi-lingualism' has been criticized by scholars such as Skutnabb-Kangas (2000) and Grosjean (1985), to name just two. Due to length considerations we will not discuss this issue in the paper.

${ }^{12}$ Smolicz $(1999,89)$ sees that children of non-English-speaking backgrounds come not empty handed, but bearing cultural gifts, chief among which are their linguistic resources.

${ }^{13}$ By 'basic literacy skills' we refer to the development of emergent reading and spelling competencies, mainly at the word level, including complex words (such as compounds).

${ }^{14}$ Recent German migrants in Australia are predominantly middle class families. Thus, the Australian context limited us to this particular social class for our pilot study.

${ }^{15}$ This discussion is beyond the scope of the present study but see Schalley, Eisenchlas, and Moyes (in preparation).

${ }^{16}$ Legend: 'Time played': each participant's accumulated actual playing time; ‘Total records': number of game events the tracking system recorded; 'Bubbles/Zoo/Handball': for each game, the number of levels the child played [out of 35/71/22 levels, respectively] and, in brackets, the overall share of participant's playing for which this accounts.

${ }^{17}$ Children were asked to add dashes in the dictation to indicate when they recognized that a sound was present but they could not provide a written representation for this sound. The stimuli included: Sofa 'sofa' /zo:fa:/, Baum 'tree' /baum/, Mund 'mouth' /mont/, Fahrrad 'bike' /fa:era:t/, Mauer 'wall' /maur/, Eimer 'bucket' /aime/, Leiter 'ladder' /laite/, Besen 'broom' /be:zən/, and Lokomotive 'railroad engine' /lokomoti:və/.

${ }^{18}$ Note that in both the pre- and post-test, the children performed the free writing task before the other tasks, so that results obtained for the free writing task were not influenced by performance of the other tasks.

${ }^{19}$ Even the all upper-case spelling of $L K W$ 'truck' is correct, as $L K W$ is the usual abbreviation for Lastkraftwagen. 
${ }^{20}$ English interference effects are still present in results for both the pre-test (e.g., carten instead of the target form Karten) and the post-test (e.g., Tea instead of German Tee). 